Journal of Animal and Veterinary Advances 11 (14): 2485-2492, 2012

ISSN: $1680-5593$

(C) Medwell Journals, 2012

\title{
Amaryllidaceae Alkaloids Exhibit Anti-Influenza Activity in MDCK Cells, an Investigation of Amaryllidaceae Alkaloids and MDCK Cells Insight
}

\author{
${ }^{1,2}$ Jun He, ${ }^{1,2}$ Wen-Bao Qi, ${ }^{1,2}$ Jin Tian, ${ }^{1,2}$ Pei-Rong Jiao, ${ }^{1,2}$ Guo-Qian Liu, \\ ${ }^{1,2}$ Chang-Hui Zhang and ${ }^{1,2}$ Ming Liao \\ ${ }^{1}$ College of Veterinary Medicine, South China Agricultural University, \\ 483 Wushan Road, 510642 Guangzhou, P.R. China \\ ${ }^{2}$ MOA Key Laboratory for Animal Vaccine Development, 510642 Guangzhou, P.R. China
}

\begin{abstract}
Influenza A viruses occasionally cause large epidemics and kill thousands every year. While little is known about the mechanism of cell fusion in diseases, especially influenza virus infected and protection from Amaryllidaceae Alkaloids. The two compounds lycorine (AA1) and haemanthamine (AA3) were obtained from bulbs of $L$. radiate, exhibited anti-influenza activity after influenza virus entry cells. The two compounds were investigated for in vitro displaying different levels of resistance to pro-apoptotic stimuli. Seven influenza viruses were used, $\mathrm{A} / \mathrm{CK} / \mathrm{GD} / 178 / 04\left(\mathrm{H}_{5} \mathrm{~N}, 178\right), \mathrm{A} / \mathrm{DK} / \mathrm{GD} / 212 / 04\left(\mathrm{H}_{5} \mathrm{~N}_{1}, 212\right), \mathrm{A} /$ swine/GD/166/06 $\left(\mathrm{H}_{3} \mathrm{~N}_{2}, 166\right)$, A/CK/HN/170/03 $\left(\mathrm{H}_{1} \mathrm{~N}_{1}, 170\right)$, A/Puerto Rico/8/34 $\left(\mathrm{H}_{1} \mathrm{~N}_{1}, \mathrm{PR} 8\right), \mathrm{A} / \mathrm{Ck} / \mathrm{GD} / 400 / 07\left(\mathrm{H}_{9} \mathrm{~N}_{2}, 400\right), \mathrm{A} / \mathrm{Ck} / \mathrm{GD} / 228 / 04$ $\left(\mathrm{H}_{9} \mathrm{~N}_{2}, 228\right)$, the two compounds exhibited potency in the single-digit micromolar range. The studies also showed that $\mathrm{AA} 1$ and $\mathrm{AA} 3$ exerted their in vitro anti-influenza activity through cytostatic rather than cytotoxic effects. Many viruses interact with the host cells to change their own growth which they favor the speed. The cells infected with virus, growth of MDCK cells was slowed down by arresting cell cycle at G1/S phase. With the compound treated, the growth cycle was decreased in $\mathrm{S}$ phase. With $\mathrm{H}_{5} \mathrm{~N}_{1}$ influenza virus treated, the cytoskeleton of cells was changed while with the compound treated the protection of cytoskeleton was obviously protected. The data showed differences between drug treated cells and virus infected cells, provided a basis to further explore cell fusion and anti-influenza mechanism of the two compounds.
\end{abstract}

$\underline{\text { Key words: Amaryllidaceae alkaloid, influenza A virus, cytoskeleton, apoptosis, epidemics, lycorine }}$

\section{INTRODUCTION}

The bulbs of Lycoris radiata have long been used as a traditional Chinese medicine in the treatment of laryngeal complications, furuncles and carbuncles (Jin, 2003). Lycorine is a pyrrolo phenanthridine ring-type alkaloid and its structure was firstly determined by Nakagawa et al. (1956). Various biological properties of lycorine and haemanthamine including inhibition of growth and cell division in higher plants, animal and algae (Jimenez et al., 1976; De Leo et al., 1973) inhibition of ascorbic acid biosynthesis (Arrigoni et al., 1975, 1997; Evidente et al., 1983, 1986) and antimalarial activity (Sener et al., 2003). Furthermore, lycorine, haemanthamine and other Amaryllidaceae small molecule constituents have been investigated for their potent anti-tumor effects and anti-leukemia effects, both in vitro and in vivo (Berkov et al., 2011; Van Goietsenoven et al., 2010; Liu et al., 2007, 2009). Previous studies have been reported lycorine and haemanthamine displayed significantly higher anti-proliferative activity in cancer than in normal cells and killed cancer cells by induction of apoptosis pathway (Liua et al., 2004; McLachlan et al., 2005; Griffin et al., 2007; Dumont et al., 2007; Ingrassia et al., 2009; Lefranc et al., 2009).

Actin was first observed and isolated by Halliburton (1987). The cutoskeletal components of host cells were changed during virus infection (DNA viruses, retroviruses and RNA viruses) involved in protein transport and RNA sorting (Cudmore et al., 1985; Rutter and Mannweiler, 1977; Tashiro et al., 1993). For cytoskeletal components of host cells were involved in protein transport and RNA sorting (Heskett and Pryme, 1991; Lafont et al., 1995; Luna and Hitt, 1992; Ojakian and Schwimmor, 1988; Sundell and Singer, 1991). Influenza virus could disrupt the stabilization of the actin cytoskeleton (Sun and Whittaker, 2007; Gottlieb et al., 1993). In the study, modifications in actin cytoskeleton organization were observed by the two compounds with computer-assisted fluorescence microscopy. Apoptosis

Corresponding Author: Ming Liao, College of Veterinary Medicine, South China Agricultural University, 483 Wushan Road, 510642 Guangzhou, P.R. China 
was induced by influenza virus infected and apoptosis was contributed to the release of the progeny influenza virus. However with the drug cultivated, apoptotic rates were decreased that may be the mechanisms of drug resistance to influenza virus. WST-1 assay was utilized to determine $\mathrm{EC}_{50}$ and growth inhibitory activity of each compound under study. Lycorine (AA1) and haemanthamine (AA3) induced changes in cell proliferation and cell cycle were monitored by means of microscopy and flow cytometry.

\section{MATERIALS AND METHODS}

Two compounds of amaryllidaceae alkaloids: The two compounds lycorine (AA1), haemanthamine (AA3) (Fig. 1, $4.67 \mu \mathrm{mol} \mathrm{L}^{-1}$ and $4.90 \mu \mathrm{mol} \mathrm{L}^{-1}$ ) were obtained from institute of Traditional Chinese Medicine and Natural Products, Jinan University, Guang zhou 510632, P.R. China. The isolation procedure for alkaloids from L. radiata was previously described (Wang et al., 2009). The purity of the two compounds was identified $>95 \%$. Plants were collected form Lanxi City, Zhejiang province of China and were identified by Min-jian Qin of the Department of Pharmacognosy, China Pharmaceutical University, Nanjing, P.R. China. A voucher specimen (No.: 2006101201) was deposited in the herbarium of China Pharmaceutical University. The two compounds dissolved in DMSO and Amaryllidaceae alkaloids (each concentration of Amaryllidaceae alkaloids contained $\mathrm{DMSO}<0.5 \%$ ).

Virus and cells line: Avian influenza virus A/CK/GD/178/04 (H5N1, GD178), A/DK/GD/212/04(H5N1, GD212), A/swine/GD/166/06 $\left(\mathrm{H}_{3} \mathrm{~N}_{2}, \mathrm{GD} 166\right), \mathrm{A} / \mathrm{CK} / \mathrm{HN} /$ $170 / 03\left(\mathrm{H}_{1} \mathrm{~N} 1, \mathrm{HN} 170\right), \mathrm{A} /$ Puerto Rico/8/34 $\left(\mathrm{H}_{1} \mathrm{~N}_{1}, \mathrm{PR} 8\right)$, $\mathrm{A} / \mathrm{Ck} / \mathrm{GD} / 400 / 07\left(\mathrm{H}_{9} \mathrm{~N}_{2}, \mathrm{GD} 400\right), \mathrm{A} / \mathrm{Ck} / \mathrm{GD} / 228 / 04\left(\mathrm{H}_{9} \mathrm{~N}_{2}\right.$, GD228) were obtained by the MOA Key Laboratory for Animal Vaccine Development, P.R. China (Table 1). MDCK cell lines were obtained from Shanghai Veterinary Research Institute (CAAS, China) were maintained in Dulbecco's Modified Eagle's Medium (DMEM, Invitrogen, USA) with $10 \%(\mathrm{v} / \mathrm{v})$ Fetal Bovine Serum (FBS, Cell Culture Bioscience, Austria). All experiments involving influenza virus were carried out in BSL-3 facilities.

Plaque-forming assay: The titers of infectious virus in culture supernatants harvested at the indicated time points were determined by plaque-forming assays. MDCK cells in a 6 well plate were infected with serial 10 fold dilutions of the virus in a serum-free medium. After washing twice with PBS, cells were overlaid with DMEM (a)

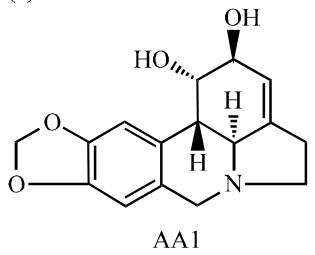

(b)

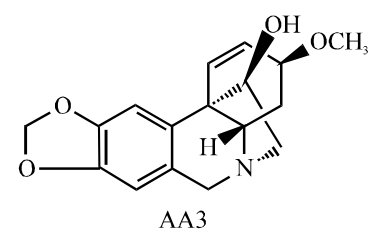

Fig. 1: Chemical structure of alkaloids; a) AA1 and b) AA3

Table 1: Antiviral activity of compounds of Amaryllidaceae Alkaloids

\begin{tabular}{|c|c|c|c|c|}
\hline \multirow[b]{3}{*}{ Virus } & \multirow{2}{*}{\multicolumn{2}{|c|}{$\begin{array}{l}\mathrm{AA} 1 \\
\mathrm{CC} 50: 20.9 \pm 0.07 \mu \mathrm{mol} \mathrm{L}^{-1}\end{array}$}} & \multirow{2}{*}{\multicolumn{2}{|c|}{$\begin{array}{l}\mathrm{AA} 3 \\
\mathrm{CC} 50: 50 \pm 0.12 \mu \mathrm{mol} \mathrm{L}\end{array}$}} \\
\hline & & & & \\
\hline & $\mathrm{EC} 50 \mu \mathrm{mol} \mathrm{L}-1$ & SI & $\mathrm{EC} 50 \mu \mathrm{mol} \mathrm{L}{ }^{-1}$ & SI \\
\hline $\mathrm{H}_{5} \mathrm{~N}_{1} \mathrm{GD} 178$ & $<0.46$ & $>45$ & $1.48 \pm 0.003$ & 34.0 \\
\hline $\mathrm{H}_{5} \mathrm{~N}_{1} \mathrm{GD} 212$ & $1.40 \pm 0.12$ & 15 & $1.61 \pm 0.050$ & 31.0 \\
\hline $\mathrm{H}_{3} \mathrm{~N}_{2} \mathrm{GD} 166$ & $3.37 \pm 0.90$ & 6.2 & $3.41 \pm 0.900$ & 14.6 \\
\hline $\mathrm{H}_{1} \mathrm{~N}_{1} \mathrm{HN} 170$ & $2.05 \pm 0.24$ & 11 & $2.05 \pm 0.200$ & 25.0 \\
\hline $\mathrm{H}_{1} \mathrm{~N}_{1} \mathrm{PR} 8$ & $6.21 \pm 2.60$ & 3.4 & - & - \\
\hline $\mathrm{H}_{9} \mathrm{~N}_{2} \mathrm{GD} 400$ & - & - & - & - \\
\hline $\mathrm{H}_{9} \mathrm{~N}_{2} \mathrm{GD} 228$ & - & - & - & - \\
\hline
\end{tabular}

$-:$ Not be detected

containing $0.8 \%(\mathrm{w} / \mathrm{v})$ low-melting agarose, $0.2 \%(\mathrm{w} / \mathrm{v})$ BSA, $2 \mu \mathrm{g} \mathrm{mL} \mathrm{m}^{-1}$ TPCK trypsin and $0.01 \%$ DEAE. After 2 days of incubation, cells were fixed with crystal violet for $1 \mathrm{~h}$ at room temperature. The plaques were counted by visual examination and the titer expressed as Plaque-Forming Units (PFU) $\mathrm{mL}^{-1}$. Means and standard deviations were calculated from three independent experiments.

Cytotoxicity assay, antiviral assay and Selectivity Index (SI): The cytotoxic effect of Amaryllidaceae alkaloids on MDCK cells was determined with WST-1 assay (Ishiyama et al., 1996). MDCK cells in 96 well plates (Corning, NY) were incubated for overnight and then with serial 2 fold dilutions of Amaryllidaceae alkaloids (each concentration of Amaryllidaceae alkaloids contained DMSO $<0.5 \%)$ in DMEM $(100 \mu \mathrm{L})$. After incubation for $72 \mathrm{~h}$, the medium was removed and CCK-8 (Cell Counting Kit-8, Dojindo Chemicals, Kumamoto, Japan) $10 \mu \mathrm{L}$ was added and incubated for $4 \mathrm{~h}$ at $37^{\circ} \mathrm{C}$, measured by scanning at 450 and $630 \mathrm{~nm}$ reference wavelengths in a Diotek microplate reader (Molecular Devices, USA). Three independent experiments were carried out and each experiment was performed in triplicate (Table 1). The percentage of viable cells was compared with untreated controls and plotted against the concentration of the two compounds and the $50 \%$ cell cytotoxic concentration was calculated according to the Reed-Muench Method.

MDCK cells were incubated in 96 well plates (Corning, NY) for $24 \mathrm{~h}$. The culture was removed and incubated the $0.01 \mathrm{MOI}(100 \mu \mathrm{L})$ virus $37^{\circ} \mathrm{C} 1 \mathrm{~h}$ and then 
removed and PBS washed three times followed by the addition of serial 2 fold dilutions of Amaryllidaceae alkaloids (each concentration was lower than $\mathrm{CC}_{50}$ and the cell activity was according to negative control cells) $(100 \mu \mathrm{L})$ per well. After incubation for $72 \mathrm{~h}$, The HA titer was used to test $50 \%$ Effective Concentration $\left(\mathrm{EC}_{50}\right)$. The Selectivity Index (SI) for each Amaryllidaceae alkaloid was calculated by dividing the $\mathrm{CC}_{50}$ by the $\mathrm{EC}_{50}\left(\mathrm{CC}_{50} / \mathrm{EC}_{50}\right)$.

Cell morphology assay and cell cycle analysis: MDCK cells were synchronized in $\mathrm{G}_{0}$ phase by serum deprivation and approximately $5 \times 10^{5} /$ well in a 6 well plate for $24 \mathrm{~h}$. Then, cells were infected with 178 influenza virus (0.1 MOI). After $1 \mathrm{~h}$ adsorption period at $37^{\circ} \mathrm{C}$, cells were washed and AA1 or AA3 was added containing $10 \% \mathrm{FBS}$ until $48 \mathrm{~h}$. Cell morphology was observed under the microscope (Leica, Germany). Cell cycle analysis was measured used cell cycle staining buffer (MultiSciences Biotech Co., Ltd.) by flow cytometry. The operation was followed by protocol. MDCK cells were fixed in $1 \mathrm{~mL}$ of cold $70 \%$ ethanol overnight at $4^{\circ} \mathrm{C}$, cells were washed and collected by treatment with trypsin then washed with PBS. Nuclear DNA content was measured using Propidium Iodide (PI) staining for $30 \mathrm{~min}$ at room temperature. PI-stained cells were then analyzed by flow cytometry.

Time of addition assay and multicycle growth inhibition assay: Pre-treatment, simultaneous treatment and posttreatment of MDCK cells were used to determine which stages of the viral life cycle were affected by the compounds. All of these influenza viruses were added at $0.01 \mathrm{MOI}$ (178 virus) to cells for $1 \mathrm{~h}$ adsorption. The supernatant was collected and tested HA titer after $72 \mathrm{~h}$.

Flow cytometric analysis for apoptosis: To determine the influence by AA1 and AA3, the extent of early apoptosis MDCK cells were tested by flow cytometry. MDCK cells were incubated in 6 well plates for $24 \mathrm{~h}$. The culture was removed and incubated $1780.1 \mathrm{MOI}(1000 \mu \mathrm{L})$ virus $37^{\circ} \mathrm{C}$ $1 \mathrm{~h}$ and then removed and PBS washed three times, AA1 and AA3 were added until $12 \mathrm{hpi}$, the operation was followed by protocol. Cell death was determined by staining cells with annexin-V and PI (Invitrogen). Flow-cytometric analysis was used and positioning of quadrants on annexin- $\mathrm{V}$ and $\mathrm{PI}$ dot plots were performed and living cells (annexin-V-/PI-), early apoptotic apoptotic cells (annexin-V+/PI-), late apoptotic apoptotic cells (annexin- $\mathrm{V}+/ \mathrm{PI}+$ ) and necrotic cells (annexin-V-/PI+) were distinguished (Vermes et al., 1995), three independent experiments were performed by Beckman Coulter FC 500. The data was analyzed on FACSCalibur (BD Bioscience).
G-actin and F-actin assays: To test the protection of cytoskeleton by AA1 and AA3, actin polymerization was measured by $\mathrm{G}$-actin and $\mathrm{F}$-actin assays. MDCK cells were grown at 6 well, cells $\left(1 \times 10^{6}\right)$ in $1000 \mu \mathrm{L}$ were exposed to virus strain 178 at an MOI of 2 and incubated at $4^{\circ} \mathrm{C}$ for $1 \mathrm{~h}$ to allow virus binding. AA1 and AA3 $(1000 \mu \mathrm{L})$ were added and cells was collected at 12 and 24 hpi. The cells were fixed with $4 \%$ paraformaldehyde for $15 \mathrm{~min}$ and permeabilized with $0.25 \%$ triton for $15 \mathrm{~min}$, washed with PBS three times and methanol once incubated with DAPI dilution (DAPI Dyeing kit, KeyGEN, China) for $15 \mathrm{~min}$ in the dark to stain nuclei.

For F-actin assay, Phalloidin-Tetramethylrhodamine $\mathrm{B}$ isothiocyanate (cat, P1951, sigma) was added to cells to stain cytoplasm for $20 \mathrm{~min}$ at $37^{\circ} \mathrm{C}$ for G-actin assay, deoxyribonuclease I, Alexa Fluor ${ }^{\circledR} 488$ conjugate (cat, D12371, molecular probes) was added to cells to stain nucleus for $20 \mathrm{~min}$ at $37^{\circ} \mathrm{C}$, removed the culture washed three times with PBS. The cells were observed using a confocal laser scanning microscope (Olympus, Japan).

Statistical analysis: All experimental groups were matched and carried out at least 2 times. Data were analyzed using Excel for determination of mean, SD and the statistical difference between the groups was determined by AVOVA.

\section{RESULTS AND DISCUSSION}

Antiviral efficacy assay: The result demonstrated that AA1 and AA3 exerted their effect at a step after virus entry into cells. AA1 and AA3 were effective against GD178, GD212, GD166, HN1 70 and PR8, a little inhibition on GD 400 and GD228 (Fig. 2a, b). The $\mathrm{CC}_{50}$ of AA1, AA3 was $20.9 \pm 0.07 \mu \mathrm{mol} \mathrm{L}-1,50 \pm 0.12 \mu \mathrm{mol} \mathrm{L}{ }^{-1}$ for $72 \mathrm{~h}$ treatment by WST-1 assay. Amaryllidaceae alkaloids was demonstrated to have similar potency against these strains, interestingly, inhibition activity of $\mathrm{H} 5$ strain was higher than other strains (Table 1).

Cytopathic Effect (CPE) protection assay: To test the protection of the drug was added to the cells at post viral adsorption, the cells were evaluated morphologically at $48 \mathrm{~h}$ pi. After influenza virus infected, MDCK cells exhibited a typical tear-like cytopathic effect. This CPE was apparently inhibited when a final concentration of $4.67 \mu \mathrm{mol} \mathrm{L}^{-1}$ (AA1) or $4.90 \mu \mathrm{mol} \mathrm{L}-1$ (AA3) was added. Meanwhile, there was no obvious change in cell morphology observed the drug treated containing the same concentration of AA1 or AA3, implying that AA1 or AA3 alone at this concentration did not have any 
cytotoxic effect but density of cells the drug treated alone was fewer than mock cells indicated that AA1 and AA3 may affect growth of MDCK cells (Fig. 3a-f).

The inhibition of apoptosis and cell cycle: Apoptosis is an important part of the release of progeny virus of influenza virus. To check whether the drug affected
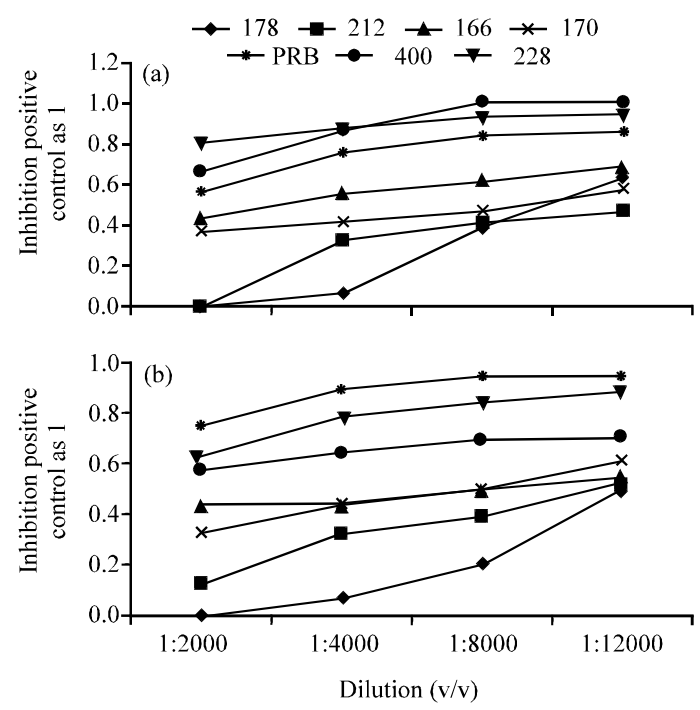

Fig. 2: Antiviral effect of AA1 or AA3 after virus entry in post assay. Seven influenza viruses at $0.01 \mathrm{MOI}$ were removed after $1 \mathrm{~h}$ adsorption and MDCK cells were treated with $\mathrm{AA} 1$ or $\mathrm{AA} 3$ at different concentration for $72 \mathrm{~h}$ at $37^{\circ} \mathrm{C}$ under $5 \% \mathrm{CO}_{2}$ atmosphere. Each concentration was assayed by two times in triplicate; a) the inhibition of AA1 at concentration $9.34,4.67,2.33$ and $1.55 \mu \mathrm{mol} \mathrm{L}^{-1}$; b) the inhibition of AA3 at concentration 9.85, 4.92, 2.46 and $1.64 \mu \mathrm{mol} \mathrm{L}^{-1}$

(a) Control

(b) $\mathrm{AA} 2$

(c) $\mathrm{AA} 3$

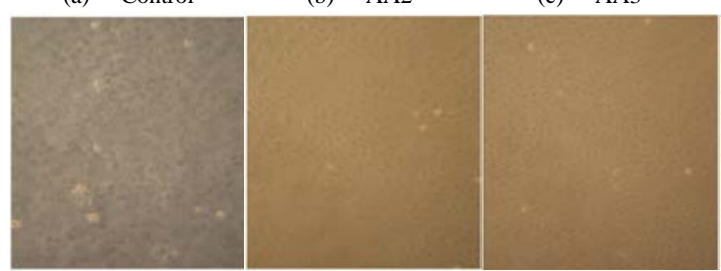

apoptosis rate induce by influenza virus. MDCK cells was stained with Anexinn $\mathrm{V}$ and PI. In virus infection group (Fig. 4a), the apoptotic rate was $18.8 \%$. In treatment of AA1, apoptotic rate was $8.4 \%$ and in AA3 treated group, apoptotic percent was $6.4 \%$. The data indicated that the two compounds of amaryllidaceae alkaloids decreased apoptosis which was the influenza virus induced. The flow cytometry assay also showed an increase in the population of cells at the $\mathrm{S}$ phase in virus infected group, after cells cultivated with the compound exhibited a decrease in S phase (Fig. 4b).

Remodeling of actin cytoskeleton was inhibited by Amaryllidaceae alkaloids: Monomeric Globular actin (G-actin) readily polymerizes to form polymeric filamentous actin (F-actin) with the concomitant hydrolysis of ATP (Taylor et al., 2011). When host cells were infected virus, the mechanisms of movement ranging from diffusion within the cytosol to active transport along cytoskeletal filaments. To determine the effect of Amaryllidaceae alkaloids on the actin cytoskeleton, $\mathrm{G}$-actin and F-actin were examined after virus infected. $\mathrm{G}$-actin polymerization and $\mathrm{F}$-actin polymerization were tested (Fig. 5a, b). With the drug treatment, G-actin and $\mathrm{F}$-actin led to an increase. The F-actin and G-actin were detected by phalloidin staining. Researchers found that influenza infection of MDCK cells also affected actin fiber formation and the ratio of F-actin to G-actin. These experiments indicated that the influence of Amaryllidaceae alkaloids protected the influenza infection leads to remodeling of the actin cytoskeleton.

Different subtypes of influenza viruses causes different cellular responses. In the data, the $\mathrm{EC}_{50}$ values in different subtypes of influenza viruses were so different. The stronger virulence, the better antiviral activity of the compound exhibited.

$\begin{array}{lll}\text { (d) } 0.1 \mathrm{MOI} 178 & \text { (e) } 178+\mathrm{AA} 2 & \text { (f) } 178+\mathrm{AA} 3\end{array}$

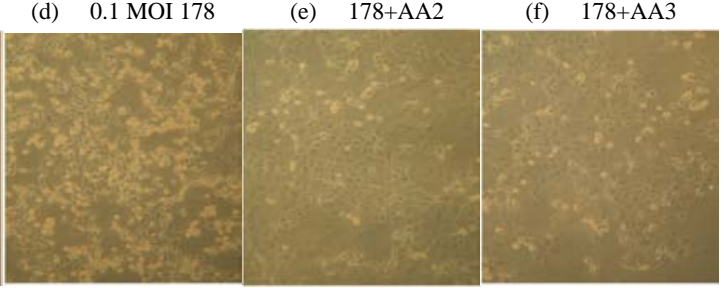

Fig. 3: Two compounds possessed antiviral activity in multiple infectious cycles. MDCK cells were adsorbed with 178 H5N1 influenza virus (MOI 0.1) for $1 \mathrm{~h}$, removed and washed three times with PBS, AA1 and AA3 was added, respectively $\left(4.67\right.$ and $\left.4.90 \mu \mathrm{mol} \mathrm{L}^{-1}\right)$. These compounds inhibit virus-induced CPE. The antiviral effect of two compounds was subsequently evaluated morphologically $48 \mathrm{hpi}$ under a light microscope. a) Mock-infected MDCK cells; b) cells incubated with AA1 only; c) cells incubated with AA3 only; d) cells infected with virus; e) cells infected with virus plus AA1; f) cells infected with virus plus AA3. The illustrations reveal cytostatic effects rather than cytotoxic ones. The concentration used here measured in WST-1 assay 

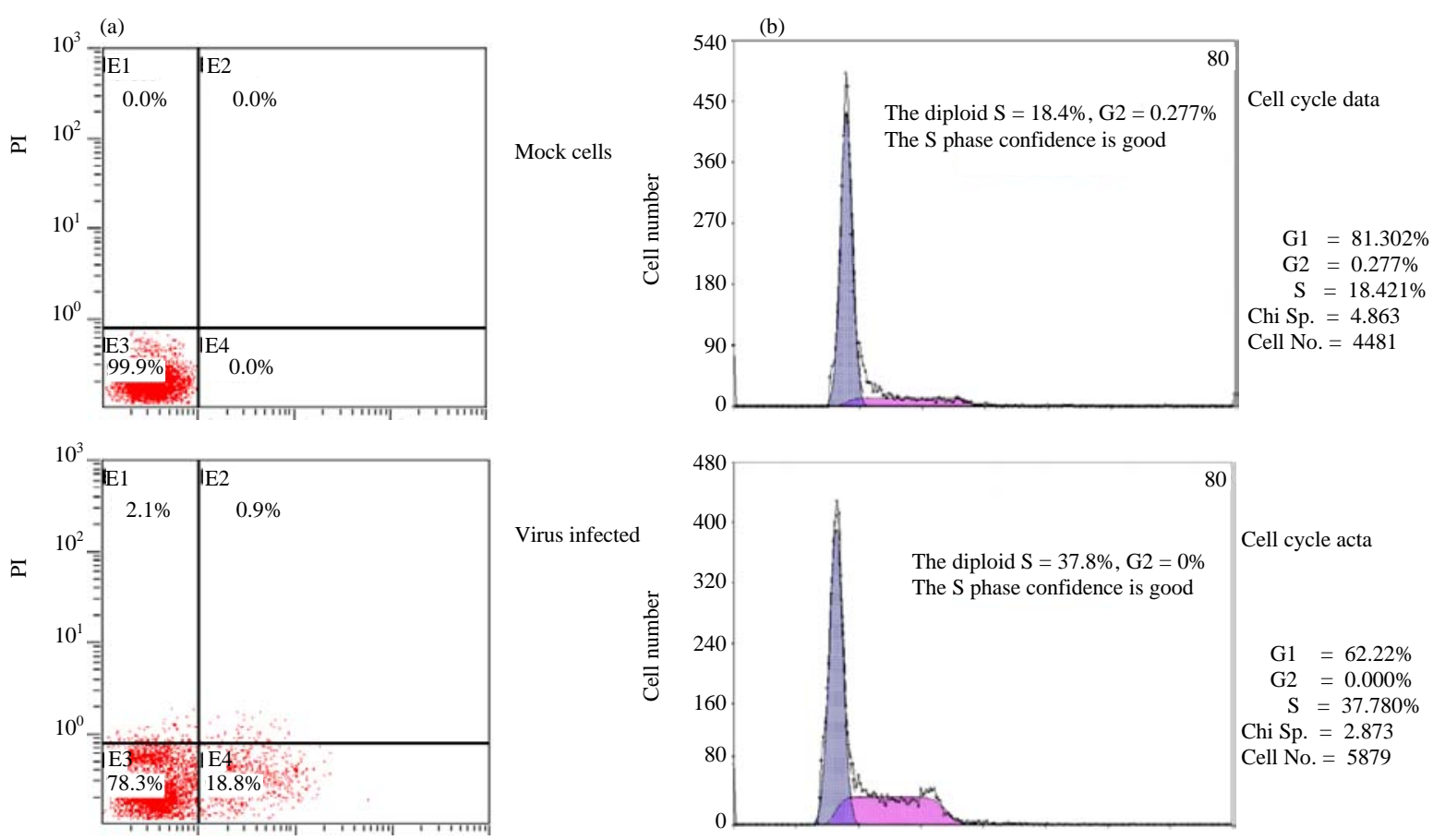

Cell cycle acta

Virus infected
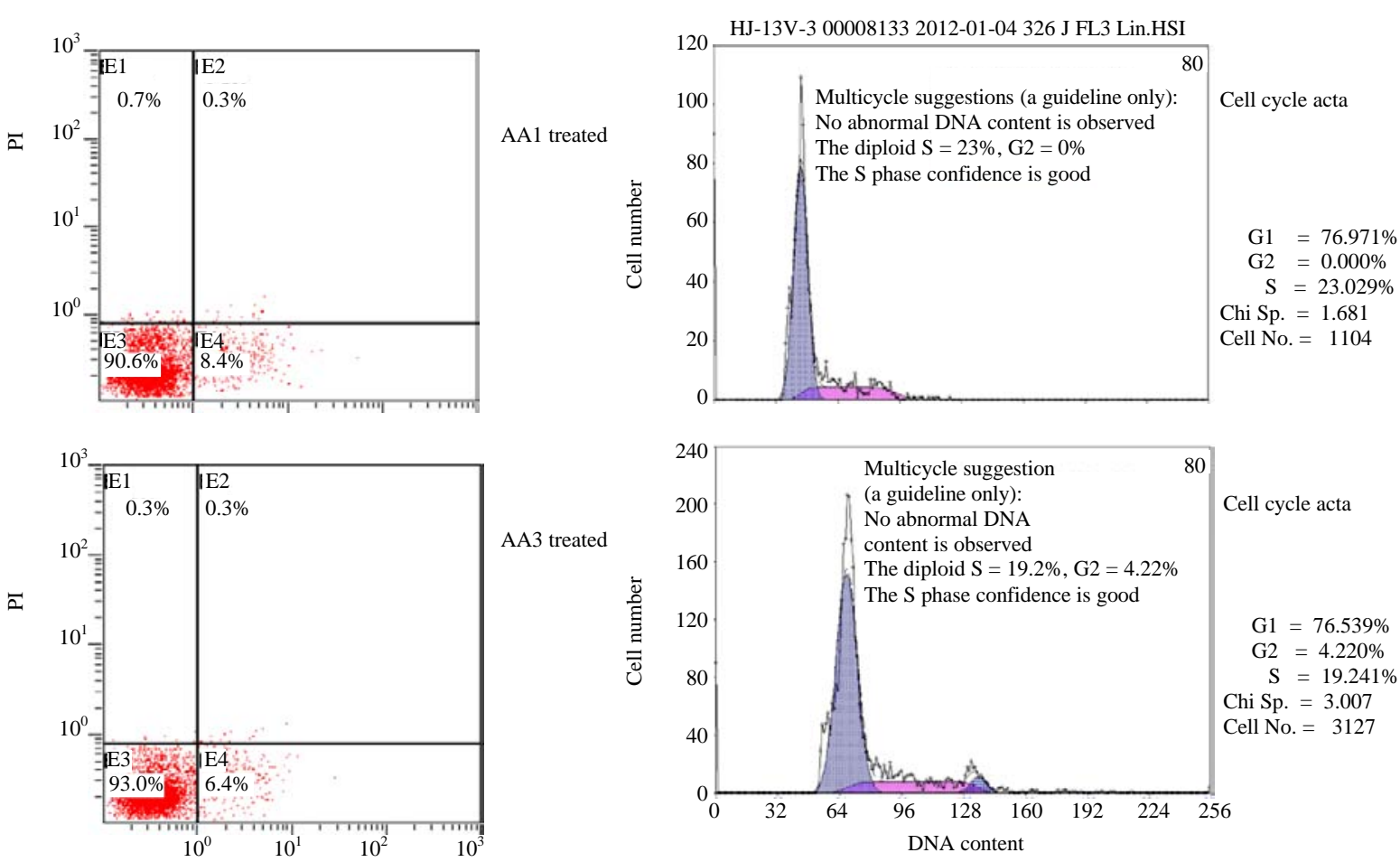

Fig. 4: AA1 $\left.(4.67 \mu \mathrm{mol} \mathrm{L})^{-1}\right)$ and AA3 $\left(4.90 \mu \mathrm{mol} \mathrm{L}^{-1}\right)$ decreased the proportion of S phase cells and apoptotic rates (178 influenza virus, MOI 0.1); a) The ratio of apoptosis in Mock cells group, virus infected group and drug treated group for $12 \mathrm{~h}$. The apoptotic percentage increased to $18.8 \%$ after infected influenza virus. The apoptotic percentage decreased to $8.4 \%$ in the treatment of AA1 group. In the treatment of AA3 group, the apoptotic percentage decreased to $6.4 \%$; b) Cell cycle distribution was measured by flow cytometry for $48 \mathrm{~h}$. The cells cultivated with the compound exhibited a decrease in $\mathrm{S}$ phase cells comparing with virus infected group. Three independent experiments were performed and results were consistent 

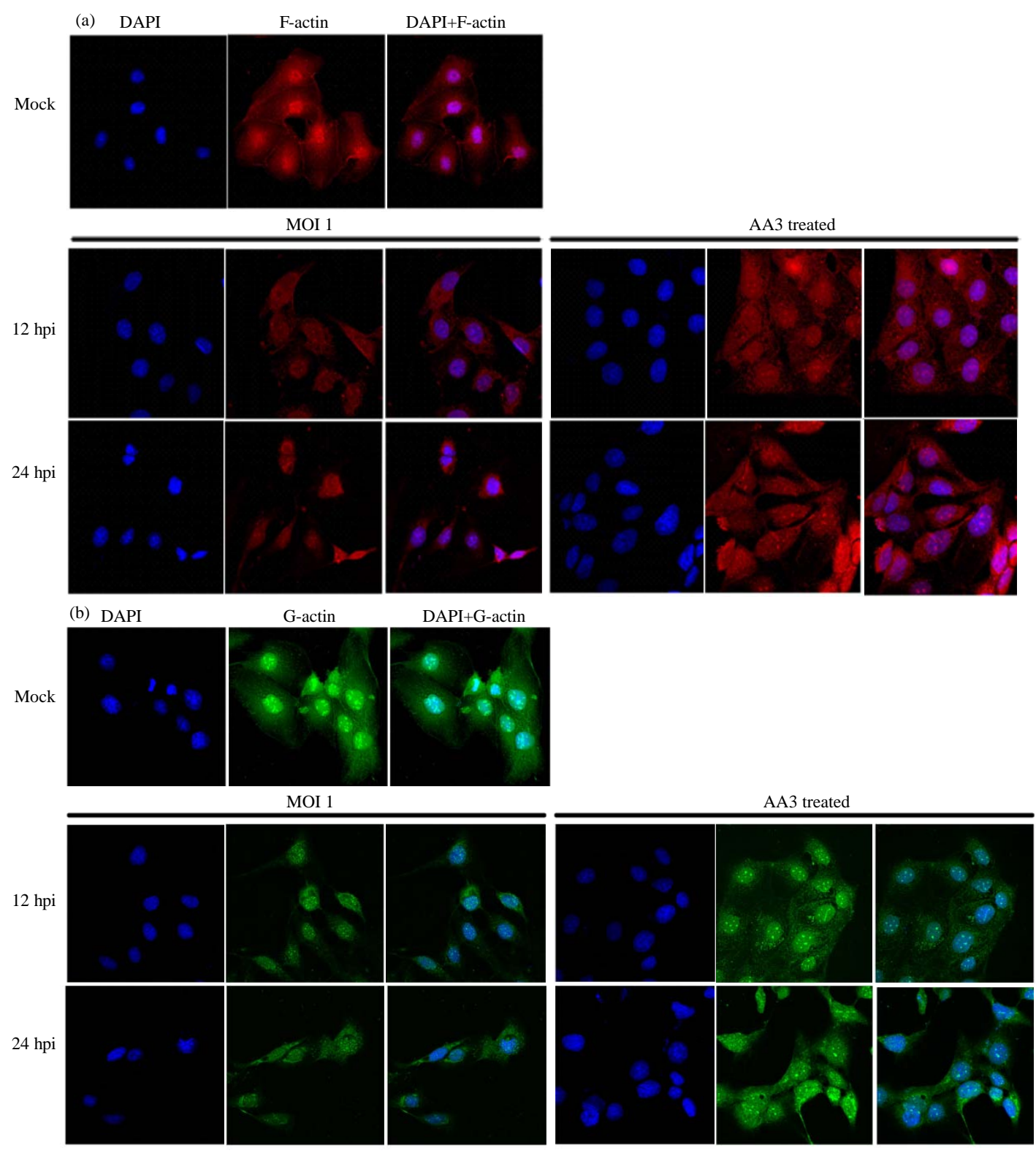

Fig. 5: Colocalization of F-actin and G-actin. Cocultured with Amaryllidaceae alkaloids during activation affected the organization of MDCK cytoskeleton. Confocal influenza infection affected actin polymerization, induced remodeling of actin cytoskeleton. MDCK cells were infected with 178 influenza virus (MOI, 2), $1 \mathrm{~h}, \mathrm{AA} 1$ or AA3 was added until $12 \mathrm{~h}$ and $24 \mathrm{hpi}$, the F-actin (red, stained cytoplasm) and G-actin (green, stained nucleus) were observated

High pathpgeneicity influenza virus caused cellular changes rapidly that may the target the drug inhibited to exert anti-influenza activity and the anti-viral activity of two compounds was performeded in the post infection. Previous reports confirmed Amaryllidaceae Alkaloids exhibited antiviral, antitumor, antimalarial and acetylcholinesterase-inhibitory activities. Some studies showed that lycorine exerted its in vitro anti-tumor activity through cytostatic and induced apoptosis. Other studies showed the opposite results (Lamoral-Theys et al., 2009). In the study, the inhibition of growth of cells was observed by cell morphology. The density of compounds treated MDCK cells decreased to two-thirds of the control after 2 days. These compounds suppressed the regeneration potential of MDCK cells. Researchers examined whether these compounds could 
interfere with cell cycles using flow cytometry. Researchers found that after AA1 and AA3 were treated with 4.67 and $4.90 \mu \mathrm{mol} \mathrm{L}^{-1}$, the percentage of cells at $\mathrm{S}$ phase decreased. Many anti-tumor reagents could arrest cell cycle and induced cell apoptosis (Purohit et al., 2000; Kessel and Luo, 2000).

Apoptosis was very important process of the release of progeny influenza virus. With AA1 and AA3 treated, apoptosis was inhibited that may the mechanism of antiviral. Influenza virus mediated transformation included deregulation of the cell cycle and advance of apoptotic pathways. With the treatment of drugs, cells that were infected and transformed by these viruses did not produce infectious progeny virions and therefore were not lysed as a result of cytopathic effects.

The actin cytoskeleton is highly dynamic. Actin persists in the cell as two different forms: G-actin and F-actin. F-actin is composed of two parallel strands of actin monomers. One significant observation of this conversion is the reconfiguration and reorganization of cellular actin. Cytoskeleton of cells was altered when virus infected.

\section{CONCLUSION}

In this study, cytoskeleton was decreased after virus infected however with drug cultivated, the cytoskeleton was consistent with control group. Current research indicates that viral interactions with the actin cytoskeleton could be targeted for new antiviral therapies and to treat virally induced disease (Liua et al., 2004). These data could provide the basis for the interaction between influenza virus and host cells that could be offered as a possible mechanism of antiviral activities.

\section{ACKNOWLEDGEMENTS}

This research was supported by the National Natural Science Foundation of China (No.: 81001375). The Natural Science Foundation of Guangdong Province (No.: 10251064201000004), Program for national broiler industry (nycytx-42-G3-03), Innovative Research Team in Chinese Universities (No.: IRT0723), Program for New Century Excellent Talents in University (Grant No.: NCET-06-0752) and the Science and Technology Projects of Guangdong Province (No:: 20100206). Jin $\mathrm{He}$ and Wen-Bao Qi contributed equally in this research.

\section{REFERENCES}

Arrigoni, O., L. De Gara, C. Paciolla, A. Evidente, M.C. De Pinto and R. Liso, 1997. Lycorine: A powerful inhibitor of L-galactono- $\gamma$-lactone dehydrogenase activity. J. Plant Physiol., 150: 362-364.
Arrigoni, O., R.A. Liso and G. Calabrese, 1975. Lycorine as an inhibitor of ascorbic acid biosynthesis. Nature, 256: 513-514.

Berkov, S., S. Romani, M. Herrera, F. Viladomat and C. Codina et al., 2011. Antiproliferative alkaloids from Crinum zeylanicum. Phytother. Res., 25: 1686-1692.

Cudmore, S., P. Cossart, G. Griffith and M. Way, 1985. Actin-based motility of vaccinia virus. Nature, 378: 636-638.

De Leo, P., G. Dalessandro, A. De Santis and O. Arrigoni, 1973. Inhibitory effect of lycorine on cell division and cell elongation. Plant Cell Physiol., 14: 487-496.

Dumont, P., L. Ingrassia, S. Rouzeau, F. Ribaucour and S. Thomas et al., 2007. The Amaryllidaceae isocarbostyril narciclasine induces apoptosis by activation of the death receptor and/or mitochondrial pathways in cancer cells but not in normal fibroblasts. Neoplasia, 9: 766-776.

Evidente, A., M.R. Cicala, G. Randazzo, R. Riccio, G. Calabrese, R. Liso and O. Arrigoni, 1983. Lycorine structure-activity relationships. Phytochemistry, 22: 2193-2196.

Evidente, A., O. Arrigoni, R. Liso, G. Calabrese and G. Randazzo, 1986. Further experiments on structureactivity relationships among the lycorine alkaloids. Phytochemistry, 25: 2739-2743.

Gottlieb, T.A., I.E. Ivanov, M. Adesnik and D.D. Sabatini, 1993. Actin microfilaments play a critical role in endocytosis at the apical but not the basolateral surface of polarized epithelial cells. J. Cell Biol., 120: 695-710.

Griffin, C., N. Sharda, D. Sood, J. Nair, J. McNulty and S. Pandey, 2007. Selective cytotoxicity of pancratistatin-related natural Amaryllidaceae alkaloids: Evaluation of the activity of two new compounds. Cancer Cell Int., Vol. 7, 10.1186/14752867-7-10

Halliburton, W.D., 1987. On muscle-plasma. J. Physiol., 8: 133-202.

Heskett, J.E. and I.F. Pryme, 1991. Interaction between mRNA, ribosomes and the cytoskeleton. J. Biochem., 277: $1-10$.

Ingrassia, L., F. Lefranc, J. Dewelle, L. Pottier and V. Mathieu et al., 2009. Structure-activity relationship analysis of novel derivatives of narciclasine (an Amaryllidaceae isocarbostyril derivative) as potentialanticancer agents. J. Med. Chem., 52: 1100-1114.

Ishiyama, M., H. Tominaga, M. Shiga, K. Sasamoto, Y. Ohkura and K. Ueno, 1996. A combined assay of cell viability and in vitro cytotoxicity with a highly water-soluble tetrazolium salt, neutral red and crystal violet. Biol. Pharm. Bull., 19: 1518-1520. 
Jimenez, A., A. Santos, Alonso G and D. Vazquez, 1976. Inhibitors of protein synthesis in eukarytic cells. Biochim. Biophys. Acta, 425: 342-348.

Jin, Z., 2003. Amaryllidaceae and Sceletium alkaloids. Nat. Prod. Rep., 20: 606-614.

Kessel, D. and Y. Luo, 2000. Cells in cryptophycininduced cell-cycle arrest are susceptible to apoptosis. Cancer Lett., 151: 25-29.

Lafont, F., J.K. Burkhard and K. Simons, 1995. Involvement of microtubule motors in basolateral and apical transport in kidney cells. Nature, 372: 801-803.

Lamoral-Theys, D. and A. Andolfi, G. Van Goietsenoven, A. Cimmino and B.L. Calve et al., 2009. Lycorine, the main phenanthridine amaryllidaceae alkaloid, exhibits significant anti-tumor activity in cancer cells that display resistance to proapoptotic stimuli: An investigation of structure-activity relationship and mechanistic insight. J. Med. Chem., 52: 6244-6256.

Lefranc, F., S. Sauvage, G. Van Goietsenoven, V. Megalizzi and D. Lamoral-Theys et al., 2009. A plant growth modulator, activates $\mathrm{Rho}$ and stress fibers in glioblastoma cells. Mol. Cancer Ther., 8: OF1-OF12.

Liu, J., Y. Li, L.J. Tang, G.P. Zhang and W.X. Hu, 2007. Treatment of lycorine on SCID mice model with human APL cells. Biomed. Pharmacother., 61: 229-234.

Liu, X.S., J. Jiang, X.Y. Jiao, Y.E. Wu, J.H. Lin and Y.M. Cai, 2009. Lycorine induces apoptosis and down-regulation of Mcl-1 in human leukemia cells. Cancer Lett., 274: 16-24.

Liua, J., W.X. Hua, L.F. Heb, M. Yec and Y. Lia, 2004. Effects of lycorine on $\mathrm{HL}-60$ cells via arresting cell cycle and inducing apoptosis. FEBS Lett., 278: $245-250$.

Luna, E.J. and A.L. Hitt, 1992. Cytoskeleton-plasma membrane interactions. Science, 258: 955-964.

McLachlan, A., N. Kekre, J. McNulty and S. Pandey, 2005. Pancratistatin: A natural Anti-cancer compound that targets mitochondria specifically in cancer cells to induce apoptosis. Apoptosis, 10: 619-630.

Nakagawa, Y., S. Uyeo and H. Yayima, 1956. The double bond in lycorine. Chem. Ind., 1956: 1238-1239.

Ojakian, G.K. and R. Schwimmor, 1988. The polarized distribution of an apical cell surface glycoprotein is maintained by interactions with the cytoskeleton of madin-darby canine kidney cells. J. Cell Biol., 107: $2377-2387$.
Purohit, A., H.A. Hejaz, L. Walden, L. MacCarthyMorrogh, G. Packham, B.V. Potter and M.J. Reed, 2000. The effect of 2-methoxyoestrone-3-Osulphamate on the growth of breast cancer cells and induced mammary tumours. Int. J. Cancer, 85: 584-589.

Rutter, G. and K. Mannweiler, 1977. Alterations of actincontaining structures in BHK21 cells infected with Newcastle disease virus and vesicular stomatitis virus. J. Gen. Virol., 37: 233-242.

Sener, B., I. Orhan and J. Satayavivad, 2003. Antimalarial activity screening of some alkaloids and the plant extracts from Amaryllidaceae. Phytother. Res., 17: $1220-1223$.

Sun, X. and G.R. Whittaker, 2007. Role of the actin cytoskeleton during influenza virus internalization into polarized epithelial cells. Cell Microbiol., 9: 1672-1682.

Sundell, C.L. and R.H. Singer, 1991. Requirement of micro?laments in sorting of actin messenger RNA. Science, 253: 1275-1277.

Tashiro, M., J.T. Seto, H.D. Klenk and R. Rott, 1993. Possible involvement of microtubule disruption in bipolar budding of a Sendai virus mutant, F1-R, in epithelial MDCK cells. J. Virol., 67: 5902-5910.

Taylor, M.P., O.O. Koyuncu and L.W. Enquist, 2011. Subversion of the actin cytoskeleton during viral infection. Nat. Rev. Microbiol., 9: 427-439.

Van Goietsenoven, G., A. Andolfi, B. Lallemand, A. Cimmino and D. Lamoral-Theys et al., 2010. Amaryllidaceae alkaloids belonging to different structural subgroups display activity against apoptosis-resistant cancer cells. J. Nat. Prod., 73: $1223-1227$.

Vermes, I., C. Haanen, H. Steffens-Nakken and C. Reutelingsperger, 1995. A novel assay for apoptosis. Flow cytometric detection of phosphatidylserine expression on early apoptotic cells using fluorescein labelled Annexin V. J. Immunol. Methods, 184: 39-51.

Wang, L., X.Q Zhang and W.C. Ye, 2009. Two new amaryllidaceae alkaloids from the bulbs of lycoris radiata. Chem. Pharm. Bull., 57: 610-611. 